\title{
One-Pot Synthesis of High-Flux b-Oriented MFI Zeolite Membranes for Xe Recovery
}

\author{
Xuerui Wang, ${ }^{*}{ }^{\dagger}$ Pelin Karakiliç, ${ }^{\dagger}$ Xinlei Liu, ${ }^{\dagger}$ Pe Meixia Shan, ${ }^{\dagger}$ Arian Nijmeijer, ${ }^{\ddagger}$ Louis Winnubst, \\ Jorge Gascon, $*,, \S \odot$ and Freek Kapteijn $*, \dagger[0$ \\ ${ }^{\dagger}$ Chemical Engineering Department, Delft University of Technology, Van der Maasweg 9, 2629 HZ Delft, The Netherlands \\ ${ }^{\ddagger}$ Inorganic Membranes, MESA+ Institute for Nanotechnology, University of Twente, P.O. Box 217, 7500 AE Enschede, The \\ Netherlands \\ ${ }^{\S}$ KAUST Catalysis Center, Advanced Catalytic Materials, King Abdullah University of Science and Technology, Thuwal 23955, \\ Saudi Arabia
}

\section{Supporting Information}

ABSTRACT: We demonstrate that $b$-oriented MFI (Mobil Five) zeolite membranes can be manufactured by in situ crystallization using an intermediate amorphous $\mathrm{SiO}_{2}$ layer. The improved in-plane growth by using a zeolite growth modifier leads to fusion of independent crystals and eliminates boundary gaps, giving good selectivity in the separation of $\mathrm{CO}_{2} / \mathrm{Xe}$ mixtures. The fast diffusion of $\mathrm{CO}_{2}$ dominates the overall membrane selectivity toward the $\mathrm{CO}_{2} / \mathrm{Xe}$ mixture. Because of the straight and short [010] channels, the obtained $\mathrm{CO}_{2}$ permeation fluxes are several orders of magnitude higher than those of carbon molecular sieving membranes and polymeric membranes, opening opportunities for Xe recovery from waste anesthetic gas.

KEYWORDS: MFI zeolite membrane, gas separation, xenon, anesthetic, carbon dioxide

\section{INTRODUCTION}

Xenon $(\mathrm{Xe})$ is considered as an attractive and better anesthetic than the standard ones used currently (such as $\mathrm{N}_{2} \mathrm{O}$ and fluoroethers) in clinical medicine because of the low risk of hypoxia, not being a neurotoxin, and the absence of "memory" effects in nerve cells. ${ }^{1}$ However, its broad application is significantly impeded by the extremely high price of Xe (5000 $\$ / \mathrm{kg})^{2}$ associated with the low abundance in the Earth's atmosphere (0.087 ppmv) and energy-intensive cryogenic distillation used in its production. ${ }^{3}$ To make Xe less costly, equilibrium-based adsorption processes using metal-organic frameworks, ${ }^{3}$ zeolites, ${ }^{4}$ or porous organic cages ${ }^{5}$ were explored to capture Xe directly from the air or discharged Xe-containing gas waste. In the case of waste anesthetic gas, Xe (50-60\% concentration) would be retrieved by selective removal of $\mathrm{CO}_{2}{ }^{6}{ }^{6}$ Given the different molecular size and affinity, microporous zeolite membranes should be able to separate the smaller $\mathrm{CO}_{2}$ molecules from the bigger Xe molecules (3.3 $\AA$ vs $4.1 \AA$ ) based on a kinetically controlled process.

Zeolites are crystalline microporous aluminosilicates with well-defined pore size and shape that have been widely used as catalysts, adsorbents, and membranes in many industrial processes, such as fluid catalytic cracking, natural gas upgrading, and bioethanol purification. ${ }^{7-9}$ Polycrystalline zeolite membranes are usually composed of anisotropic crystals with accessible apertures and channels randomly aligned within the membrane layer, which limits access to the pores and increases diffusion path lengths. ${ }^{10}$ The development of synthetic protocols that allow the alignment of zeolite pores with the membrane surface is therefore of high interest.

Crystals of the archetype all-silica MFI zeolite exhibit hexagonal platelet morphologies with distinct surfaces, the $(100)$ and $(010)$ faces, and a third surface $(x 0 z)$ with a variable Miller index. The diffusion coefficient along the straight [010] channel is approximately three times higher than that on the channel perpendicular to this direction. ${ }^{11}$ Thus, $b$-oriented MFI zeolite membranes with straight and short [010] channels are highly desired to maximize permeance (throughput) and separation factor (selectivity) simultaneously. Yoon et al. ${ }^{12,13}$ developed different methods for orientation-controlled monolayer assembly of zeolite crystals via covalent linkers or hand rubbing, which facilitate $b$-oriented MFI zeolite membrane formation by secondary growth. ${ }^{14,15}$ Subsequently, various approaches were developed to construct $b$-oriented MFI crystal/nanosheet layers, involving dynamic interfacial assembly, ${ }^{16-18}$ polymer-mediated assembly, ${ }^{19}$ and LangmuirSchaefer $^{20}$ or Langmuir-Blodgett ${ }^{21}$ deposition. An unparalleled MFI zeolite membrane with $200 \mathrm{~nm}$ thickness was

Received: July 25, 2018

Accepted: September 11, 2018

Published: September 11, 2018 

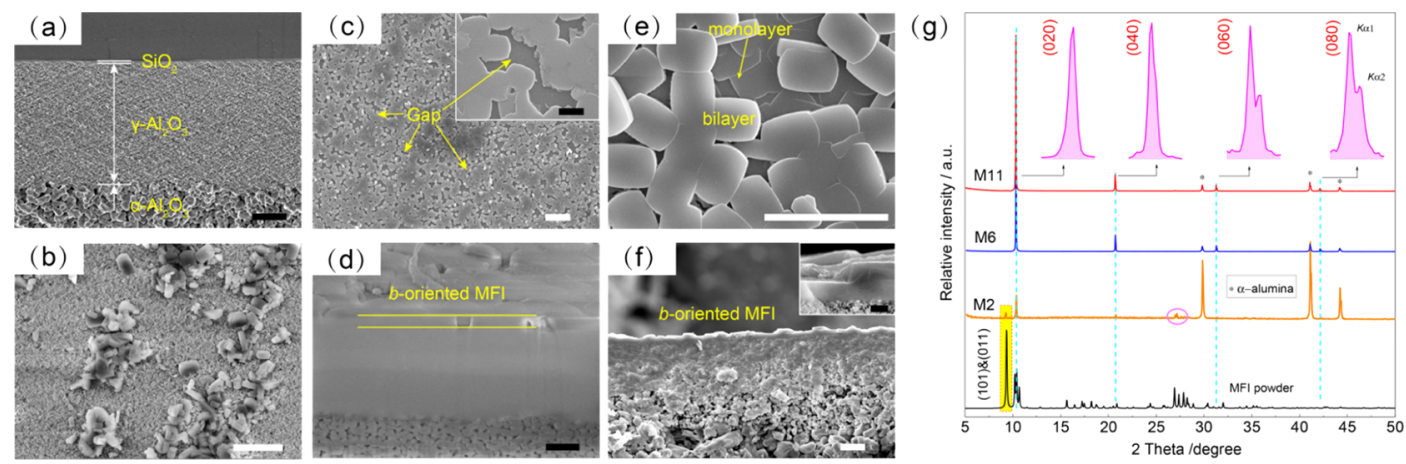

Figure 1. SEM and PXRD characterization of $b$-oriented MFI zeolite membranes; (a) silica-coated alumina support; (b) random-oriented MFI zeolite membrane on the bare alumina support synthesized for $8 \mathrm{~h}, \mathrm{M} 2$; $(\mathrm{c}, \mathrm{d}) b$-oriented MFI zeolite membrane on silica-coated alumina support synthesized for $3 \mathrm{~h}$ without TBPO, M6; (e,f) $b$-oriented MFI zeolite membrane on silica-coated alumina support synthesized for $6 \mathrm{~h}$ with 0.1 wt $\%$ TBPO, M11; scale bar in white and black color: 10 and $1 \mu \mathrm{m}$; (g) PXRD patterns of random- and $b$-oriented MFI zeolite membranes. Synthesis condition: $1 \mathrm{TEOS} / 0.2 \mathrm{TPAOH} / 110 \mathrm{H}_{2} \mathrm{O}$ at $150{ }^{\circ} \mathrm{C}$.

achieved via secondary growth of a zeolite nanosheet layer, obtained by filtration of high-aspect-ratio zeolite nanosheet suspension. $^{22,23}$ Despite these elegant approaches, a costeffective and easy-to-scale-up methodology for the production of $b$-oriented MFI zeolite membranes is still to be developed.

In addition to cumbersome seeding, another main challenge is to avoid orthogonal rotational intergrowth of MFI zeolite during the hydrothermal synthesis. ${ }^{15,23}$ Yang et al. ${ }^{24}$ pioneered microwave irradiation heating to prepare $b$-oriented MFI films in short synthesis times. Replacement of the traditional structure-directing agent (SDA) tetrapropylammonium hydroxide by bis- $N, N$-(tripropylammoniumhexamethylene) di$\mathrm{N}, \mathrm{N}$-propylammonium trihydroxide (trimer-TPAOH) ${ }^{14}$ triethanolamine, $^{25}$ and tetraethylammonium hydroxide ${ }^{15,21}$ has been investigated to enhance the epitaxial growth of $b$-oriented MFI seeds. Neutral ${ }^{26}$ and fluoride-containing ${ }^{15,27,28}$ solutions were explored as well to suppress the orthogonally rotational intergrowth of $b$-oriented MFI seeds during secondary growth. Recently, it was demonstrated that water vapor can trigger the epitaxial growth of $b$-oriented MFI seeds when using a sacrificial silica layer impregnated with SDAs as an interphase and $\mathrm{Si}$ source, eliminating the gaps within the crystal/ nanosheet layer and resulting in highly selective $b$-oriented MFI zeolite membranes. ${ }^{29}$

Herein, we present a versatile in situ crystallization approach to manufacture $b$-oriented MFI zeolite membranes on porous alumina supports. An amorphous silica layer was precoated by dip-coating, which would be further transformed to a $b$ oriented MFI zeolite membrane during the following, one step, hydrothermal treatment. We chose tributylphosphine oxide (TBPO) as the zeolite growth modifier (ZGM) instead of the complex trimer-TPAOH ${ }^{14}$ or environmental hazardous $\mathrm{HF}^{15,27,28}$ to improve the in-plane growth of MFI crystals within the membrane, leading to a bigger $b$-face dimension, which facilitates the fusion of independent crystals and eliminates boundary gaps. The aim of this study was not only to provide a preparation methodology of $b$-oriented MFI zeolite membranes, but also to demonstrate the medical applicability of these membranes in Xe recovery.

\section{EXPERIMENTAL SECTION}

2.1. Materials. The following chemicals from Sigma-Aldrich were used as received without any purification: TPAOH $(1.0 \mathrm{M}$ solution in water), tetraethyl orthosilicate (TEOS, 98\%), and TBPO (95\%). Ammonium fluoride $\left(\mathrm{NH}_{4} \mathrm{~F}, 96 \%\right)$ was supplied by VWR Interna- tional BV. Macroporous $\alpha-\mathrm{Al}_{2} \mathrm{O}_{3}$ discs with a diameter of $25 \mathrm{~mm}$, a thickness of $2 \mathrm{~mm}$, a porosity of $35 \%$, and a pore size of $80 \mathrm{~nm}$ were supplied from Pervatech B. V. The Netherlands. Silica-coated $\alpha-\mathrm{Al}_{2} \mathrm{O}_{3}$ plate supports $(25 \mathrm{~mm}$ diameter, top silica layer of $1 \mathrm{~nm}$ pores, and a thicker bottom of $2.5 \mu \mathrm{m}$ pores) were purchased from Fraunhofer IKTS Hermsdorf.

2.2. Preparation of Silica-Coated Alumina Supports. A mesoporous $\gamma-\mathrm{Al}_{2} \mathrm{O}_{3}$ intermediate layer with a pore size of $5 \mathrm{~nm}$ and a thickness of $3 \mu \mathrm{m}$ was prepared by dip-coating the macroporous $\alpha$ $\mathrm{Al}_{2} \mathrm{O}_{3}$ discs into a solution composed of boehmite and polyvinyl alcohol under cleanroom conditions (class 100); then, the discs were calcined at $650{ }^{\circ} \mathrm{C}$ for $3 \mathrm{~h}$ with a heating and cooling rate of $1{ }^{\circ} \mathrm{C} /$ min. The dip-coating and calcination were performed twice. The silica sol was prepared by an acid-catalyzed sol-gel reaction of TEOS in ethanol and nitric acid under continuous stirring for $3 \mathrm{~h}$ at $60{ }^{\circ} \mathrm{C}$. After the reaction, the silica sol was diluted with ethanol to have the final molar ratio of $1 \mathrm{TEOS} / 3.8 \mathrm{EtOH} / 6.2 \mathrm{H}_{2} \mathrm{O} / 0.085 \mathrm{HNO}_{3}$. Then, the $\gamma-\mathrm{Al}_{2} \mathrm{O}_{3}$-coated discs were dipped into the silica sol, followed by calcination at $600{ }^{\circ} \mathrm{C}$ for $3 \mathrm{~h}$ with a heating and cooling rate of 0.5 ${ }^{\circ} \mathrm{C} / \mathrm{min}$. The dip-coating and calcination processes were repeated once more to form a smooth microporous silica layer with a pore size of around $0.5 \mathrm{~nm}$ and a thickness of 70-100 nm (Figure 1a). Further details of the preparation of silica membranes can be found in our previous paper. $^{30}$

2.3. Preparation of $b$-Oriented MFI Zeolite Membranes. MFI zeolite membranes were prepared by in situ crystallization from a clear solution with a molar composition of $1 \mathrm{SiO}_{2} / 0.2 \mathrm{TPAOH} / 110 \mathrm{H}_{2} \mathrm{O}$ / 4 EtOH. TPAOH was added to deionized water followed by dropwise addition of TEOS. The mixture was stirred at room temperature for at least $6 \mathrm{~h}$. Then, $0-0.5 \mathrm{wt} \%$ TBPO based on the total weight of the solution was added. The solution was transferred to a $45 \mathrm{~mL}$ Teflonlined autoclave, wherein a silica-coated alumina disc was vertically placed. The autoclave was then placed in an oven preheated to 150 ${ }^{\circ} \mathrm{C}$. After crystallization for a specific period, the membrane and powder were recovered and thoroughly washed with deionized water and ethanol. The different synthesis conditions for all the membranes are listed in Table S1. The silica gel attached on the top surface was removed by washing with $0.2 \mathrm{M}$ ammonium fluoride for $4 \mathrm{~h}$. The SDA of $\mathrm{TPA}^{+}$was removed by calcination: in the case of membranes, calcination was conducted at $400{ }^{\circ} \mathrm{C}$ for $2 \mathrm{~h}$ with a heating and cooling rate of $1{ }^{\circ} \mathrm{C} / \mathrm{min}$; however, $550{ }^{\circ} \mathrm{C}$ for $10 \mathrm{~h}$ was used for powders.

2.4. Crystallographic Preferred Orientation. The preferred orientation of MFI crystals within the membrane layer was evaluated by crystallographic preferred orientation $(\mathrm{CPO}), \mathrm{CPO}_{(020) /(501)}$, based on powder X-ray diffraction (PXRD) patterns, which is defined in the following way 


$$
\mathrm{CPO}_{(020) /(501)}=\frac{I_{(020)}^{\text {membrane }} / I_{(501)}^{\text {membrane }}-I_{(020)}^{\text {powder }} / I_{(501)}^{\text {powder }}}{I_{(020)}^{\text {membrane }} / I_{(501)}^{\text {membrane }}}
$$

where $I_{(020)}^{\text {membrane }}$ and $I_{(501)}^{\text {membrane }}$ refer to the intensity of the $(020)$ and the (501) peaks of the membrane, whereas $I_{(020)}^{\text {owder }}$ and $I_{(501)}^{\text {powder }}$ refer to the peak intensity of the MFI powder. If a peak was not detected, the intensity of that peak was set to 1 count/step according to the report of Hedlund et al. ${ }^{31}$

2.5. Gas Separation Performance. The as-synthesized $b$ oriented MFI zeolite membrane was sealed into a stainless steel cell using a Viton O-ring. The effective membrane area for permeation was $3.14 \mathrm{~cm}^{2}$. The temperature was controlled by an oven from room temperature to $200{ }^{\circ} \mathrm{C}$. $\mathrm{He}, \mathrm{CO}_{2}, \mathrm{~N}_{2}, \mathrm{Ar}, \mathrm{Xe}$, and $\mathrm{SF}_{6}$ single gas permeation through the membranes was measured in a steady-state gas permeation setup. The pressure at the feed side (absolute pressure ranging from 1.2 to 3 bar) was controlled using a back-pressure controller and the permeate side was connected to a bubble flow meter at atmospheric pressure (absolute pressure of $1 \mathrm{bar}$ ) without sweep gas. The gas permeance $\left(P_{i}\right.$, GPU) and ideal selectivity $\left(S_{i j}\right)$ are defined as follows

$$
\begin{gathered}
P_{i}=\frac{J_{i}}{\Delta p_{i}} \\
S_{i j}=\frac{P_{i}}{P_{j}}
\end{gathered}
$$

where $J_{i}$ is the permeation flux through the membrane, $\mathrm{mol} \cdot \mathrm{m}^{-2} \cdot \mathrm{s}^{-1}$; $\Delta p_{i}$ is the transmembrane pressure difference of component $i, \mathrm{~Pa}$.

For $\mathrm{CO}_{2} / \mathrm{Xe}$ mixtures, the permeation was investigated by the Wicke-Kallenbach technique. The total feed flow rate was $55 \mathrm{~mL} /$ min. Ar was used as sweep gas with a constant volumetric flow rate of $60 \mathrm{~mL} / \mathrm{min}$ to eliminate concentration polarization and carry the permeate to a two-channel gas chromatograph (Interscience Compact GC) for composition determination. The channel equipped with a ShinCarbon ST 80/100 column $(1 \mathrm{~m} \times 0.53 \mathrm{~mm})$ and a thermal conductivity detector was used to separate and analyze $\mathrm{CO}_{2}$ and $\mathrm{Xe}$. At each permeation condition, the system was stabilized for more than $2 \mathrm{~h}$ and the measurement was repeated with at least 10 injections. The permeance is defined using the same equation as single-gas permeation. The separation factor $\left(\alpha_{i j}\right)$ is defined by the following equation

$$
\alpha_{i j}=\frac{y_{i} / y_{j}}{x_{i} / x_{j}}
$$

where $x_{i}, x_{j}, y_{i}$ and $y_{j}$ are the molar fractions of the components at the feed side and permeate side, respectively.

2.6. Characterization. The morphology of MFI zeolite powder and membrane was observed by scanning electron microscopy (SEM, JSM-6010LA, JEOL). Prior to SEM analysis of the MFI zeolite membrane, a trench was milled in the membrane by accelerating concentrated gallium ions $(30 \mathrm{kV}, 0.75 \mathrm{nA})$ using a Dual Beam 3 Nova 200 focused ion beam (FIB). Atomic force microscopy (AFM) images were collected in noncontact tapping mode using a Solver NEXT AFM instrument from NT-MDT. A silicon cantilever (HA_NC/50) with spring constants ranging from 0.4 to $2.7 \mathrm{~N} / \mathrm{m}$ (resonant frequency of $140 \mathrm{kHz}$ ) was used. Nova Px 3.2.5 software was used for all of the data acquisition and analysis. PXRD patterns were recorded in a Bruker-D8 ADVANCE diffractometer using Co $\mathrm{K} \alpha$ radiation $(\lambda=1.78897 \AA)$. The $2 \theta$ range of $5^{\circ}-50^{\circ}$ was scanned using a scan rate of $0.05^{\circ} \cdot \mathrm{s}^{-1}$. Furthermore, $\mathrm{Ar}$ isotherm at $87 \mathrm{~K}$ was acquired with a 3 Flex (Micromeritics) apparatus using high-purity Ar. The sample was first degassed under dry nitrogen flow at $350{ }^{\circ} \mathrm{C}$ for $10 \mathrm{~h}$.

\section{RESULTS AND DISCUSSION}

3.1. b-Oriented MFI Zeolite Formation from Amorphous Silica Layer Transition. MFI crystals were sparsely and randomly packed as hillocks on the bare alumina support after in situ crystallization (Figures $1 \mathrm{~b}$ and $\mathrm{S} 1 \mathrm{a}, \mathrm{b}$ ), in line with the previous report. ${ }^{32}$ Interestingly, a uniformly $b$-oriented MFI monolayer was obtained when an intermediate silica coating was applied to the alumina support (Figures 1c, S1c,d, and S2). The average crystal sizes along the $a$ and $c$ axes were $1.2 \mu \mathrm{m} \times 0.9 \mu \mathrm{m}$, respectively, giving a lateral size of $1.08 \mu \mathrm{m}^{2}$. The monolayer structure was well confirmed by an FIB-SEM image of the cross section, showing a thickness of $350 \mathrm{~nm}$ (Figures 1d and S3). The nucleation of MFI zeolite crystals is believed to start at the interface of the silica gel layer and the TPAOH-containing solution; ${ }^{33}$ the crystallization proceeds until the monolayer structure anchors on the support. ${ }^{34}$ It should be noted that the amorphous silica layer was partially dissolved and transformed into crystalline MFI crystals during the in situ crystallization. The reactivity of such a silica layer was further proved by the formation of $b$-oriented MFI crystals after hydrothermal treatment in a TPAOH solution in the absence of any additional Si source (Figure S4).

The visible gaps within the $b$-oriented MFI monolayer can be mitigated by extending the synthesis time (Figure S5) while still maintaining the $b$-orientation, as evidenced by a $\mathrm{CPO}_{(020) /(501)}$ value higher than $99.6 \%$ (Table S2). ${ }^{31}$ However, defect-free membranes could not be achieved, which is the result of the slowed down in-plane growth of MFI crystals anchoring on the supports. ${ }^{34}$ We believe that this is the reason why a $b$-oriented MFI zeolite film is merely achieved by in situ crystallization on an impermeable silicon wafer, ${ }^{34}$ glass, ${ }^{35}$ and alloy substrates ${ }^{36}$ but not on porous support for separation.

3.2. Improved in-Plane Growth by ZGMs. Generally, twinning growth is an inherent growth behavior for MFI zeolites, which results from the orthogonally rotational intergrowth along the $c$-axis or addition of nanoparticles to the $b$-face. ${ }^{21,23,37}$ However, when 0.1 wt \% TBPO was added to the synthesis solution, $b$-oriented MFI zeolite membranes without visible gaps were achieved by in situ crystallization at $150{ }^{\circ} \mathrm{C}$ for $6 \mathrm{~h}$ (Figure 1e). TBPO was chosen because of its highest efficiency over the other commercial ZGMs in reducing the [010] dimension of MFI zeolite. ${ }^{38}$ The membrane structure in this case is slightly more complex, as additional $b$-oriented MFI crystals formed on top of the primary monolayer, as clearly observed by SEM imaging of the membrane cross section (Figure 1f): $1.1 \pm 0.1 \mu \mathrm{m}$ for the monolayer and $2.2 \pm 0.3 \mu \mathrm{m}$ for the bilayer. The thickness increases further with synthesis time; for example, a membrane layer composed of bilayered and trilayered MFI zeolite crystals was obtained after in situ crystallization of $10 \mathrm{~h}$ (Figure S6a,b).

Only the diffraction peaks from the (020), (040), (060), and (080) faces could be observed from the PXRD patterns (Figures $1 \mathrm{~g}$ and S6c), further proving $b$-orientation of the MFI crystals. The splitting of the latter two diffraction peaks is due to the presence of two different wavelengths in the X-ray source $\left(\mathrm{Co} \mathrm{K} \alpha_{1}\right.$ and $\mathrm{K} \alpha_{2}$ ). To visualize the effect of TBPO on the in-plane growth of MFI zeolite, the lateral size versus synthesis time is plotted in Figure 2. The lateral size of MFI crystals linearly increases with synthesis time. Interestingly, the $b$-face dimension is always larger than that without ZGMs. An increment of $210 \%$ was achieved in the lateral size after addition of 0.1 wt $\%$ TBPO, affording a well-intergrown $b$ oriented MFI monolayer with a $b$-face area of $11.9 \mu \mathrm{m}^{2}$. The improved in-plane growth is responsible for the elimination of visible gaps within the monolayer. 


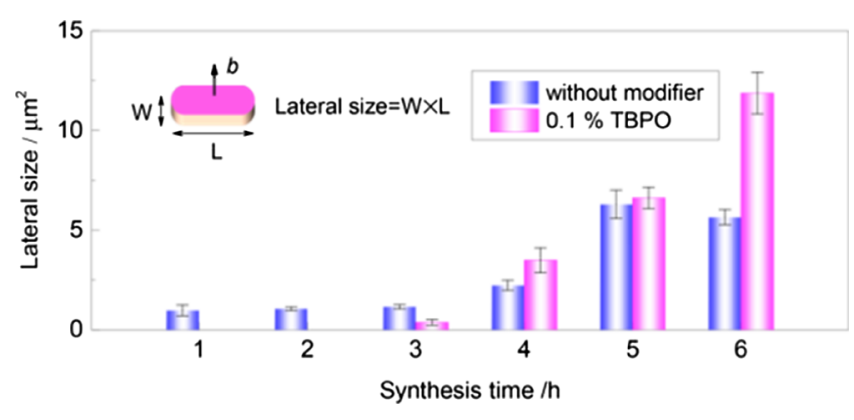

Figure 2. Lateral size of the crystals within $b$-oriented MFI zeolite membranes. Synthesis condition: 1 TEOS/0.2 TPAOH/110 $\mathrm{H}_{2} \mathrm{O}$ at $150{ }^{\circ} \mathrm{C}$.

3.3. Role of ZGMs. To understand the role of TBPO in the nucleation and growth, solid-state ${ }^{29} \mathrm{Si}-\mathrm{NMR}$ and $\mathrm{Ar}$ adsorption was conducted using MFI zeolite powder. Generally, a defective MFI zeolite would give a peak at $\delta=$ $-102 \mathrm{ppm}$, which is ascribed to Q3 $\mathrm{Si}$ atoms bearing silanol groups. ${ }^{27}$ However, we only observed the multiple peaks in the region between $\delta=-110$ and $-117 \mathrm{ppm}$, arising from the Q4 $\mathrm{Si}$ atoms (Figure 3a). ${ }^{39}$ Previously, Tsapatsis et al. ${ }^{40}$ reported that tetrabutylphosphonium hydroxide (TBPOH) triggers the rotational intergrowth of single-unit cell MFI lamellae, leading to a house-of-cards arrangement with a hierarchical structure containing micropores and mesopores simultaneously. The $\mathrm{Ar}$ isotherm at $87 \mathrm{~K}$ proves a uniform microporous structure and the absence of mesopores in our case (Figure $3 b$ ). AFM was further used to detect the surface morphology of the membrane. Terraces with a thickness of $1.5 \pm 0.1 \mathrm{~nm}$ (Figure $3 c$ ) are clearly observed from the $b$-face, indicating that terrace spreading rather than surface nucleation dominates crystal growth. $^{41}$ However, hillocks with a height of $15 \mathrm{~nm}$ were observed in the case of TBPO-free solution (Figure 3d), which can be well explained by the nonclassical growth mechanism of silicalite-1 (all-silica MFI zeolite) based on the aggregation of metastable silica nanoparticle precursors. ${ }^{37}$

On the basis of the above results, we propose the following role for TBPO (Figure 3e): TBPO molecules would cover the surface of wet silica nanoparticles by hydrogen bonding of the $\mathrm{P}=\mathrm{O}$ groups to adsorbed water molecules and surface silanol groups. The maximal surface coverage of TBPO molecules on wet silica is as high as $43 \% .{ }^{49}$ The isolated silica nanoparticles would not participate in MFI zeolite nucleation and growth; thus, we speculate the isolation effect of TBPO leads to a lower concentration of active silica species and therefore delayed nucleation and mitigated twinning growth. ${ }^{25}$ In this line, nucleation and intergrowth within the membrane layer were significantly slowed down in the presence of TPBO (Figure S7). This also explains why a longer synthesis time was used to achieve continuous $b$-oriented MFI membranes. Meanwhile, the $b$-face of the MFI crystal is potentially favorable for the adsorption of ZGMs as proved by density functional theory calculation $^{50}$ and experimental results. ${ }^{38}$ The adsorbed TBPO molecules on $b$-faces impede the addition of soluble silica units (classical mechanism) and agglomerated precursors (nonclassical mechanism) until they are replaced by SDAs, leading to a mitigated twinning growth and the enhancement of inplane growth. ${ }^{38,51}$ The absence of phosphorus in the membrane demonstrates that TBPO acts as a surface modifier rather than as SDA [X-ray photoelectron spectroscopy (XPS) results, Figure S8].

3.4. Single Gas Permeation. $\mathrm{N}_{2}$ permeance was as low as $1.4 \mathrm{GPU}\left(1 \mathrm{GPU}=3.3928 \times 10^{-10} \mathrm{~mol} \cdot \mathrm{m}^{-2} \cdot \mathrm{s}^{-1} \cdot \mathrm{Pa}^{-1}\right)$ for the SDA-containing membrane, demonstrating the absence of pinholes (open symbol in Figure 4a). After complete removal of SDAs (Figure S9), single gas permeances decrease in the sequence of $\mathrm{He}, \mathrm{N}_{2}, \mathrm{CO}_{2}, \mathrm{Ar}, \mathrm{Xe}$, and $\mathrm{SF}_{6}$; they are independent of the transmembrane pressure difference (Figure S10), indicating the absence of viscous flow. A clear cutoff was observed at a kinetic diameter of $\sim 5 \AA$. The ideal selectivity of these light gas molecules over $\mathrm{SF}_{6}$ is always higher than Knudsen selectivity (Figure 4b, Table S3), further demonstrating a dense membrane layer. It is worth noting that the in situ crystallization approach exhibited a good reproducibility to prepare $b$-oriented MFI zeolite membranes (Figure 4d), which is essential for the practical production.

3.5. Separation of $\mathrm{CO}_{2} / \mathrm{Xe}$ Mixture. Despite great achievements in separation of $\mathrm{Xe}$ from $\mathrm{Kr}$ or air by chabazite SAPO-34, ${ }^{45,52-54}$ AIPO-18, ${ }^{53}$ and ZIF-8 membranes, ${ }^{53,55,56}$ $\mathrm{CO}_{2} / \mathrm{Xe}$ mixture separation using microporous membranes has been overlooked in the past decades. ${ }^{46}$ Herein, we propose a novel Xe recovery approach from exhaled anesthetic gas based on $b$-oriented MFI zeolite membranes. This can be used to
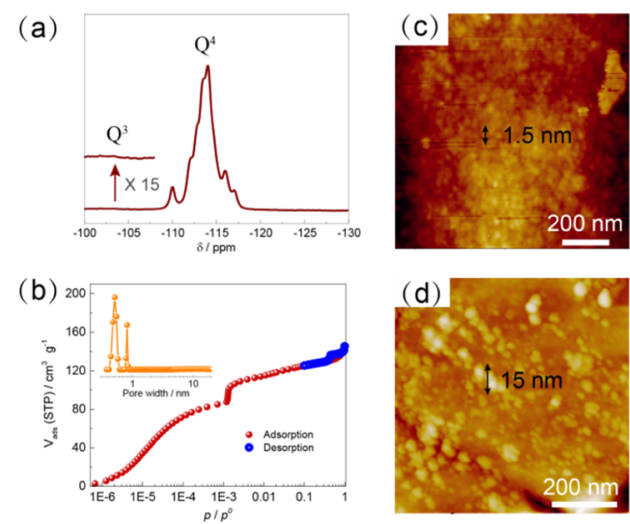

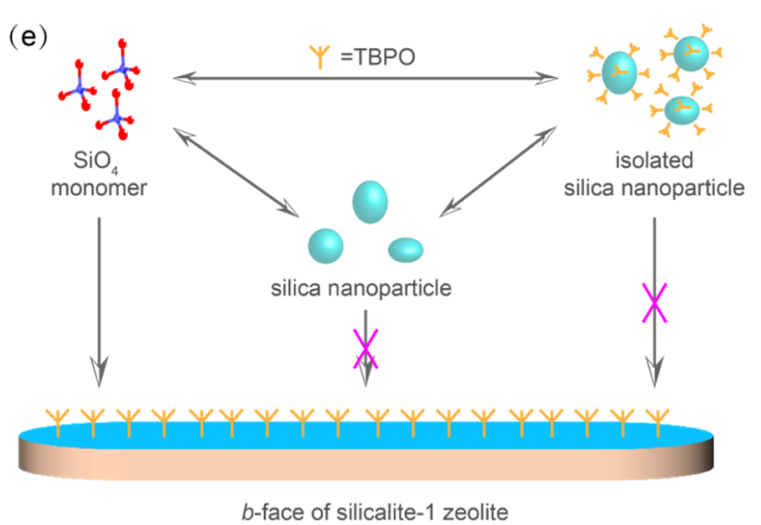

Figure 3. Mechanism of TBPO in the nucleation and growth of MFI crystals; $(\mathrm{a}-\mathrm{c})$ magic angle spinning ${ }^{29} \mathrm{Si}$ NMR spectrum, Ar isotherm at 87 $\mathrm{K}$, and AFM image of the $b$-face of MFI crystals synthesized from the solution containing $0.1 \mathrm{wt} \%$ TBPO for $6 \mathrm{~h}$; the steep step at $p / p_{0}=10^{-3}$ is arising from the fluid-to-crystalline-like phase transition of the adsorbed phase in the MFI micropores; (d) AFM image of the $b$-face of MFI crystals synthesized from TBPO-free solution for $3 \mathrm{~h}$. Scale bars in white and black color indicate lateral and height dimension, respectively; (e) illustration of the role of TBPO in MFI crystal nucleation and growth. Synthesis condition: 1 TEOS/0.2 TPAOH/110 $\mathrm{H}_{2} \mathrm{O}$ at $150{ }^{\circ} \mathrm{C}$. 
(a)

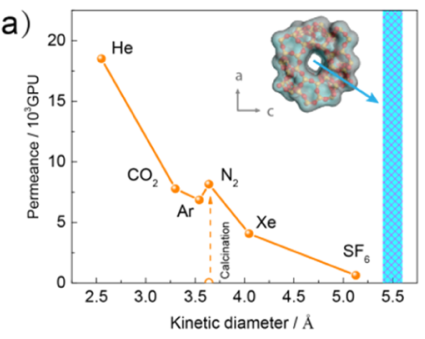

(c)

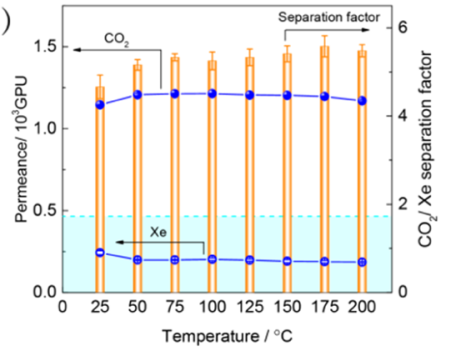

(b)
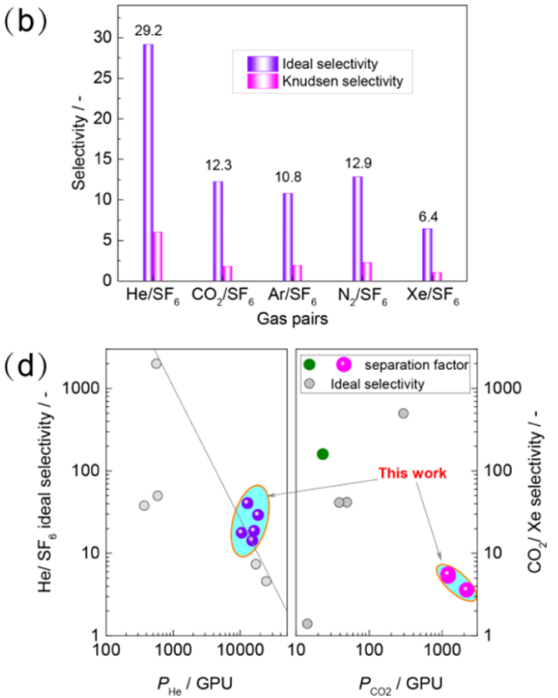

Figure 4. Separation performance of $b$-oriented MFI zeolite membranes; (a,b) Single gas permeance and ideal selectivity of $b$-oriented MFI zeolite membrane M11 under an absolute feed pressure of 2 bar and room temperature; (c) temperature-dependent separation performance of $b$-oriented MFI zeolite membrane M11 for 50/50 $\mathrm{CO}_{2} / \mathrm{Xe}$ mixture at an absolute feed pressure of 1.5 bar; the cyan colour indicates Knudsen selectivity of $\mathrm{CO}_{2} / \mathrm{Xe}(1.7)$; (d) comparison of five membrane performance in this work with other membranes, involving random-oriented MFI, ${ }^{42-44} \mathrm{SAPO}$ $34{ }^{45}$ carbon molecular sieving, ${ }^{46} \mathrm{PIMs}^{47}$ and $\mathrm{PDMS}^{48}$ (raw data are shown in Tables S3-S5).

continuously remove the major impurity of $\mathrm{CO}_{2}$ from the closed-circuit anesthesia system. As shown in Figure 4c, the separation factor of $\mathrm{CO}_{2}$ to $\mathrm{Xe}$ was 5.6, higher than the ideal and Knudsen selectivity. The permeance of pure $\mathrm{CO}_{2}$ exhibits a maximum as a function of temperature (Figure S11d), proving surface diffusion dominates $\mathrm{CO}_{2}$ transport in MFI channels. ${ }^{57}$ Like for other adsorptive gas mixtures in MFI, ${ }^{58,59}$ the competitive adsorption between $\mathrm{CO}_{2}$ and $\mathrm{Xe}$ plays an important role in $\mathrm{CO}_{2} / \mathrm{Xe}$ mixture separation. The preferential adsorption of $\mathrm{Xe}$ by MFI zeolite (Figure S12) would compromise $\mathrm{CO}_{2}$ transport through the membranes, leading to much lower permeance than in the case of single gas. ${ }^{45,58}$ As the mixed gas selectivity factor is higher than the ideal gas selectivity, the $\mathrm{CO}_{2}$-selective separation is attributed to the high $\mathrm{CO}_{2}$ diffusivity in MFI zeolite as demonstrated by breakthrough studies. ${ }^{4,58}$ This is further supported by the slight increase of separation factor with temperature, which is the result of a stronger reduction in Xe adsorption because of its higher heat of adsorption than that of $\mathrm{CO}_{2}{ }^{4}$ The same situation applies for $\mathrm{Kr} / \mathrm{Xe}$ separation in other nanoporous crystalline membranes, such as ZIF-8 and SAPO-34, as elucidated by molecular simulation. ${ }^{60}$

The ideal selectivity of $\mathrm{CO}_{2} / \mathrm{Xe}$ could be as high as $\sim 500$ for the benchmark eight-member-ring zeolite membranes, for example, SAPO- 34 ; $^{45}$ however, the gas permeance would be significantly deteriorated by the mixed gas. For example, the permeance was merely $11.5 \mathrm{GPU}^{45}$ and $17.1 \mathrm{GPU}^{54}$ for $\mathrm{Kr} / \mathrm{Xe}$ mixtures. The same situation occurred for carbon molecular sieving membranes ${ }^{46}$ and polymeric membranes [e.g., polymer inclusion membrane (PIM), PIM- ${ }^{47}$ and PIM-7, ${ }^{47}$ and polydimethylsiloxane (PDMS) ${ }^{48}$ for the separation of $\mathrm{CO}_{2} /$ Xe. The $b$-oriented MFI zeolite membrane in this work exhibited a $\mathrm{CO}_{2}$ permeance of $1213 \mathrm{GPU}$, which is several orders of magnitude higher than that of the above membranes (Figure 4d). The higher permeation flux would significantly reduce the investment of membrane-based units and their footprint. The good reproducibility and long-term hydrothermal stability ( $>260$ h, Figure S13) endow b-oriented MFI zeolite membranes with a great potential for practical application of Xe recovery from exhaled anesthetic gas.

\section{CONCLUSIONS}

In summary, we have reported a facile in situ crystallization for the manufacture of $b$-oriented MFI zeolite membranes. The membrane exhibited an exceptional $\mathrm{CO}_{2}$ permeation flux because of the short and oriented straight channels. The onepot synthesis approach in this study paves a way to prepare $b$ oriented MFI zeolite membranes, showing great potential for application. The demonstrated Xe recovery from $\mathrm{CO}_{2}$ allows its increased use as an anesthetic in medical application.

\section{ASSOCIATED CONTENT}

\section{S Supporting Information}

The Supporting Information is available free of charge on the ACS Publications website at DOI: 10.1021/acsami.8b12613.

Detailed description of supporting characterizations (SEM, PXRD, XPS, FTIR, TGA, gas permeation property) used in the present study (PDF)

\section{AUTHOR INFORMATION}

\section{Corresponding Authors}

*E-mail: x.wang-12@tudelft.nl (X.W.).

*E-mail: jorge.gascon@kaust.edu.sa (J.G.).

*E-mail: f.kapteijn@tudelft.nl (F.K.).

ORCID $\odot$

Xuerui Wang: 0000-0003-2220-7531

Xinlei Liu: 0000-0001-7552-1597

Jorge Gascon: 0000-0001-7558-7123

Freek Kapteijn: 0000-0003-0575-7953

\section{Author Contributions}

The paper was written through contributions of all the authors. All the authors have given approval to the final version of the manuscript. 


\section{Notes}

The authors declare no competing financial interest.

\section{ACKNOWLEDGMENTS}

This work is financially supported by STW, The Netherlands (Project number 13941). The authors thank Bart van der Linden (Delft University of Technology, TUD), Willy Rook (TUD), and Liliana Baron (TUD) for their help with gas separation performance and gas uptake measurements.

\section{REFERENCES}

(1) Franks, N. P. General Anaesthesia: From Molecular Targets to Neuronal Pathways of Sleep and Arousal. Nat. Rev. Neurosci. 2008, 9, 370-386.

(2) Elsaidi, S. K.; Ongari, D.; Xu, W.; Mohamed, M. H.; Haranczyk, M.; Thallapally, P. K. Xenon Recovery at Room Temperature using Metal-Organic Frameworks. Chem.-Eur. J. 2017, 23, 10758-10762. (3) Banerjee, D.; Simon, C. M.; Elsaidi, S. K.; Haranczyk, M.; Thallapally, P. K. Xenon Gas Separation and Storage Using MetalOrganic Frameworks. Chem 2018, 4, 466-494.

(4) Deliere, L.; Coasne, B.; Topin, S.; Gréau, C.; Moulin, C.; Farrusseng, D. Breakthrough in Xenon Capture and Purification Using Adsorbent-Supported Silver Nanoparticles. Chem.-Eur. J. 2016, 22, 9660-9666.

(5) Chen, L.; Reiss, P. S.; Chong, S. Y.; Holden, D.; Jelfs, K. E.; Hasell, T.; Little, M. A.; Kewley, A.; Briggs, M. E.; Stephenson, A.; Thomas, K. M.; Armstrong, J. A.; Bell, J.; Busto, J.; Noel, R.; Liu, J.; Strachan, D. M.; Thallapally, P. K.; Cooper, A. I. Separation of Rare Gases and Chiral Molecules by Selective Binding in Porous Organic Cages. Nat. Mater. 2014, 13, 954-960.

(6) Goto, T.; Nakata, Y.; Morita, S. Will Xenon Be a Stranger or a Friend? Anesthesiology 2003, 98, 1-2.

(7) Moliner, M.; Martínez, C.; Corma, A. Multipore Zeolites: Synthesis and Catalytic Applications. Angew. Chem., Int. Ed. 2015, 54, 3560-3579.

(8) Kuznicki, S. M.; Bell, V. A.; Nair, S.; Hillhouse, H. W.; Jacubinas, R. M.; Braunbarth, C. M.; Toby, B. H.; Tsapatsis, M. A Titanosilicate Molecular Sieve with Adjustable Pores for Size-Selective Adsorption of Molecules. Nature 2001, 412, 720-724.

(9) Yuan, W.; Lin, Y. S.; Yang, W. Molecular Sieving MFI-Type Zeolite Membranes for Pervaporation Separation of Xylene Isomers. J. Am. Chem. Soc. 2004, 126, 4776-4777.

(10) Rangnekar, N.; Mittal, N.; Elyassi, B.; Caro, J.; Tsapatsis, M. Zeolite membranes - a review and comparison with MOFs. Chem. Soc. Rev. 2015, 44, 7128-7154.

(11) Caro, J.; Noack, M.; Richter-Mendau, J.; Marlow, F.; Petersohn, D.; Griepentrog, M.; Kornatowski, J. Selective sorption uptake kinetics of n-hexane on ZSM 5 - a new method for measuring anisotropic diffusivities. J. Phys. Chem. 1993, 97, 13685-13690.

(12) Kulak, A.; Lee, Y.-J.; Park, Y. S.; Yoon, K. B. OrientationControlled Monolayer Assembly of Zeolite Crystals on Glass and Mica by Covalent Linkage of Surface-Bound Epoxide and Amine Groups. Angew. Chem., Int. Ed. 2000, 39, 950-953.

(13) Lee, J. S.; Kim, J. H.; Lee, Y. J.; Jeong, N. C.; Yoon, K. B. Manual Assembly of Microcrystal Monolayers on Substrates. Angew. Chem., Int. Ed. 2007, 46, 3087-3090.

(14) Lai, Z.; Bonilla, G.; Diaz, I.; Nery, J. G.; Sujaoti, K.; Amat, M. A.; Kokkoli, E.; Terasaki, O.; Thompson, R. W.; Tsapatsis, M.; Vlachos, D. G. Microstructural Optimization of a Zeolite Membrane for Organic Vapor Separation. Science 2003, 300, 456-460.

(15) Pham, T. C. T.; Kim, H. S.; Yoon, K. B. Growth of Uniformly Oriented Silica MFI and BEA Zeolite Films on Substrates. Science 2011, 334, 1533-1538.

(16) Liu, Y.; Li, Y.; Yang, W. Fabrication of Highly b-Oriented MFI Film with Molecular Sieving Properties by Controlled In-Plane Secondary Growth. J. Am. Chem. Soc. 2010, 132, 1768-1769.
(17) Zhou, M.; Hedlund, J. Oriented Monolayers of Submicron Crystals by Dynamic Interfacial Assembly. J. Mater. Chem. 2012, 22, 3307-3310.

(18) Kim, D.; Jeon, M. Y.; Stottrup, B. L.; Tsapatsis, M. para -Xylene Ultra-selective Zeolite MFI Membranes Fabricated from Nanosheet Monolayers at the Air-Water Interface. Angew. Chem., Int. Ed. 2018, 57, 480-485.

(19) Zhang, B.; Zhou, M.; Liu, X. Monolayer Assembly of Oriented Zeolite Crystals on $\alpha$-Al2O3 Supported Polymer Thin Films. Adv. Mater. 2008, 20, 2183-2189.

(20) Rangnekar, N.; Shete, M.; Agrawal, K. V.; Topuz, B.; Kumar, P.; Guo, Q.; Ismail, I.; Alyoubi, A.; Basahel, S.; Narasimharao, K.; Macosko, C. W.; Mkhoyan, K. A.; Al-Thabaiti, S.; Stottrup, B.; Tsapatsis, M. 2D Zeolite Coatings: Langmuir-Schaefer Deposition of $3 \mathrm{~nm}$ Thick MFI Zeolite Nanosheets. Angew. Chem., Int. Ed. 2015, 54, 6571-6575.

(21) Shete, M.; Kumar, M.; Kim, D.; Rangnekar, N.; Xu, D.; Topuz, B.; Agrawal, K. V.; Karapetrova, E.; Stottrup, B.; Al-Thabaiti, S.; Basahel, S.; Narasimharao, K.; Rimer, J. D.; Tsapatsis, M. Nanoscale Control of Homoepitaxial Growth on a Two-Dimensional Zeolite. Angew. Chem., Int. Ed. 2017, 56, 535-539.

(22) Varoon, K.; Zhang, X.; Elyassi, B.; Brewer, D. D.; Gettel, M.; Kumar, S.; Lee, J. A.; Maheshwari, S.; Mittal, A.; Sung, C.-Y.; Cococcioni, M.; Francis, L. F.; McCormick, A. V.; Mkhoyan, K. A.; Tsapatsis, M. Dispersible Exfoliated Zeolite Nanosheets and Their Application as a Selective Membrane. Science 2011, 334, 72-75.

(23) Jeon, M. Y.; Kim, D.; Kumar, P.; Lee, P. S.; Rangnekar, N.; Bai, P.; Shete, M.; Elyassi, B.; Lee, H. S.; Narasimharao, K.; Basahel, S. N.; Al-Thabaiti, S.; Xu, W.; Cho, H. J.; Fetisov, E. O.; Thyagarajan, R.; DeJaco, R. F.; Fan, W.; Mkhoyan, K. A.; Siepmann, J. I.; Tsapatsis, M. Ultra-Selective High-Flux Membranes from Directly Synthesized Zeolite Nanosheets. Nature 2017, 543, 690-694.

(24) Liu, Y.; Li, Y.; Cai, R.; Yang, W. Suppression of Twins in $b$ Oriented MFI Molecular Sieve Films under Microwave Irradiation. Chem. Commun. 2012, 48, 6782-6784.

(25) Fu, D.; Schmidt, J. E.; Ristanović, Z.; Chowdhury, A. D.; Meirer, F.; Weckhuysen, B. M. Highly Oriented Growth of Catalytically Active Zeolite ZSM-5 Films with a Broad Range of Si/ Al Ratios. Angew. Chem., Int. Ed. 2017, 56, 11217-11221.

(26) Peng, Y.; Lu, X.; Wang, Z.; Yan, Y. Fabrication of b-Oriented MFI Zeolite Films under Neutral Conditions without the Use of Hydrogen Fluoride. Angew. Chem., Int. Ed. 2015, 54, 5709-5712.

(27) Pham, T. C. T.; Kim, H. S.; Yoon, K. B. Large Increase in the Second-Order Nonlinear Optical Activity of a HemicyanineIncorporating Zeolite Film. Angew. Chem., Int. Ed. 2013, 52, 55395543.

(28) Zhou, M.; Korelskiy, D.; Ye, P.; Grahn, M.; Hedlund, J. A Uniformly Oriented MFI Membrane for Improved CO2Separation. Angew. Chem., Int. Ed. 2014, 53, 3492-3495.

(29) Pham, T. C. T.; Nguyen, T. H.; Yoon, K. B. Gel-Free Secondary Growth of Uniformly Oriented Silica MFI Zeolite Films and Application for Xylene Separation. Angew. Chem., Int. Ed. 2013, 52, 8693-8698.

(30) Karakiliç, P.; Huiskes, C.; Luiten-Olieman, M. W. J.; Nijmeijer, A.; Winnubst, L. Sol-gel processed magnesium-doped silica membranes with improved $\mathrm{H} 2 / \mathrm{CO} 2$ separation. J. Membr. Sci. 2017, 543, 195-201.

(31) Hedlund, J.; Mintova, S.; Sterte, J. Controlling the Preferred Orientation in Silicalite-1 Films Synthesized by Seeding. Microporous Mesoporous Mater. 1999, 28, 185-194.

(32) Zhang, F.-Z.; Fuji, M.; Takahashi, M. In Situ Growth of Continuous b-Oriented MFI Zeolite Membranes on Porous $\alpha$ Alumina Substrates Precoated with a Mesoporous Silica Sublayer. Chem. Mater. 2005, 17, 1167-1173.

(33) den Exter, M. J.; van Bekkum, H.; Rijn, C. J. M.; Kapteijn, F.; Moulijn, J. A.; Schellevis, H.; Beenakker, C. I. N. Stability of Oriented Silicalite-1 Films in View of Zeolite Membrane Preparation. Zeolites 1997, 19, 13-20. 
(34) Jansen, J. C.; van Rosmalen, G. M. Oriented Growth of Silica Molecular Sieve Crystals as Supported Films. J. Cryst. Growth 1993, 128, 1150-1156.

(35) Kim, H. S.; Lee, S. M.; Ha, K.; Jung, C.; Lee, Y.-J.; Chun, Y. S.; Kim, D.; Rhee, B. K.; Yoon, K. B. Aligned Inclusion of Hemicyanine Dyes into Silica Zeolite Films for Second Harmonic Generation. J. Am. Chem. Soc. 2004, 126, 673-682.

(36) Wang, Z.; Yan, Y. Controlling Crystal Orientation in Zeolite MFI Thin Films by Direct in Situ Crystallization. Chem. Mater. 2001, 13, 1101-1107.

(37) Lupulescu, A. I.; Rimer, J. D. In Situ Imaging of Silicalite-1 Surface Growth Reveals the Mechanism of Crystallization. Science 2014, 344, 729-732.

(38) Lupulescu, A. I.; Rimer, J. D. Tailoring Silicalite-1 Crystal Morphology with Molecular Modifiers. Angew. Chem., Int. Ed. 2012, 51, 3345-3349.

(39) Fyfe, C. A.; Gobbi, G. C.; Klinowski, J.; Thomas, J. M.; Ramdas, S. Resolving Crystallographically Distinct Tetrahedral Sites in Silicalite and ZSM-5 by Solid-State NMR. Nature 1982, 296, 530533.

(40) Zhang, X.; Liu, D.; Xu, D.; Asahina, S.; Cychosz, K. A.; Agrawal, K. V.; Al Wahedi, Y.; Bhan, A.; Al Hashimi, S.; Terasaki, O.; Thommes, M.; Tsapatsis, M. Synthesis of Self-Pillared Zeolite Nanosheets by Repetitive Branching. Science 2012, 336, 1684-1687.

(41) Meza, L. I.; Anderson, M. W.; Agger, J. R.; Cundy, C. S.; Chong, C. B.; Plaisted, R. J. Controlling Relative Fundamental Crystal Growth Rates in Silicalite: AFM Observation. J. Am. Chem. Soc. 2007, 129, 15192-15201.

(42) Lassinantti, M.; Jareman, F.; Hedlund, J.; Creaser, D.; Sterte, J. Preparation and Evaluation of Thin ZSM-5 Membranes Synthesized in the Absence of Organic Template Molecules. Catal. Today 2001, 67, 109-119.

(43) Rezai, S. A. S.; Lindmark, J.; Andersson, C.; Jareman, F.; Möller, K.; Hedlund, J. Water/Hydrogen/Hexane Multicomponent Selectivity of Thin MFI Membranes with Different Si/Al Ratios. Microporous Mesoporous Mater. 2008, 108, 136-142.

(44) Kanezashi, M.; O’Brien, J.; Lin, Y. S. Template-Free Synthesis of MFI-Type Zeolite Membranes: Permeation Characteristics and Thermal Stability Improvement of Membrane Structure. J. Membr. Sci. 2006, 286, 213-222.

(45) Hye Kwon, Y.; Kiang, C.; Benjamin, E.; Crawford, P.; Nair, S.; Bhave, R. Krypton-xenon separation properties of SAPO-34 zeolite materials and membranes. AIChE J. 2017, 63, 761-769.

(46) Lagorsse, S.; Magalhães, F. D.; Mendes, A. Xenon Recycling in an Anaesthetic Closed-System Using Carbon Molecular Sieve Membranes. J. Membr. Sci. 2007, 301, 29-38.

(47) Budd, P.; Msayib, K.; Tattershall, C.; Ghanem, B.; Reynolds, K.; McKeown, N.; Fritsch, D. Gas Separation Membranes from Polymers of Intrinsic Microporosity. J. Membr. Sci. 2005, 251, 263269.

(48) Malankowska, M.; Martins, C. F.; Rho, H. S.; Neves, L. A.; Tiggelaar, R. M.; Crespo, J. G.; Pina, M. P.; Mallada, R.; Gardeniers, H.; Coelhoso, I. M. Microfluidic devices as gas - Ionic liquid membrane contactors for $\mathrm{CO} 2$ removal from anaesthesia gases. J. Membr. Sci. 2018, 545, 107-115.

(49) Yerushalmi, R.; Ho, J. C.; Fan, Z.; Javey, A. Phosphine Oxide Monolayers on SiO2 Surfaces. Angew. Chem., Int. Ed. 2008, 47, 44404442.

(50) Shan, Z.; Wang, H.; Meng, X.; Liu, S.; Wang, L.; Wang, C.; Li, F.; Lewis, J. P.; Xiao, F.-S. Designed Synthesis of TS-1 Crystals with Controllable $b$-Oriented Length. Chem. Commun. 2011, 47, 10481050.

(51) Li, R.; Smolyakova, A.; Maayan, G.; Rimer, J. D. Designed Peptoids as Tunable Modifiers of Zeolite Crystallization. Chem. Mater. 2017, 29, 9536-9546.

(52) Feng, X.; Zong, Z.; Elsaidi, S. K.; Jasinski, J. B.; Krishna, R.; Thallapally, P. K.; Carreon, M. A. Kr/Xe Separation over a Chabazite Zeolite Membrane. J. Am. Chem. Soc. 2016, 138, 9791-9794.
(53) Wu, T.; Lucero, J.; Zong, Z.; Elsaidi, S. K.; Thallapally, P. K.; Carreon, M. A. Microporous Crystalline Membranes for $\mathrm{Kr} / \mathrm{Xe}$ Separation: Comparison Between AlPO-18, SAPO-34, and ZIF-8. ACS Appl. Nano Mater. 2018, 1, 463-470.

(54) Kwon, Y. H.; Min, B.; Yang, S.; Koh, D.-Y.; Bhave, R. R.; Nair, S. Ion-Exchanged SAPO-34 Membranes for Krypton-Xenon Separation: Control of Permeation Properties and Fabrication of Hollow Fiber Membranes. ACS Appl. Mater. Interfaces 2018, 10, 6361-6368.

(55) Wu, T.; Lucero, J.; Sinnwell, M. A.; Thallapally, P. K.; Carreon, M. A. Recovery of Xenon from Air over ZIF-8 Membranes. Chem. Commun. 2018, 54, 8976-8979.

(56) Wu, T.; Feng, X.; Elsaidi, S. K.; Thallapally, P. K.; Carreon, M. A. Zeolitic Imidazolate Framework-8 (ZIF-8) Membranes for Kr/Xe Separation. Ind. Eng. Chem. Res. 2017, 56, 1682-1686.

(57) Kapteijn, F.; van de Graaf, J. M.; Moulijn, J. A. OneComponent Permeation Maximum: Diagnostic Tool for Silicalite-1 Membranes? AIChE J. 2000, 46, 1096-1100.

(58) van de Graaf, J. M.; Kapteijn, F.; Moulijn, J. A. Modeling Permeation of Binary Mixtures through Zeolite Membranes. AIChE J. 1999, 45, 497-511.

(59) Kapteijn, F.; Moulijn, J. A.; Krishna, R. The Generalized Maxwell-Stefan Model for Diffusion in Zeolites: Sorbate Molecules with Different Saturation Loadings. Chem. Eng. Sci. 2000, 55, 29232930.

(60) Anderson, R.; Schweitzer, B.; Wu, T.; Carreon, M. A.; GómezGualdrón, D. A. Molecular Simulation Insights on Xe/Kr Separation in a Set of Nanoporous Crystalline Membranes. ACS Appl. Mater. Interfaces 2018, 10, 582-592. 